\title{
Effect of Various Laser Surface Treatments on Repair Shear Bond Strength of Aged Silorane-Based Composite
}

\author{
Parnian Alizadeh Oskoee ${ }^{1}$, Siavash Savadi Oskoee ${ }^{1}$, Sahand Rikhtegaran ${ }^{1}$, Fatemeh Pournaghi-Azar ${ }^{1}$, Sarah \\ Gholizadeh $^{2 *}$, Yasaman Aleyasin ${ }^{3}$, Shahin Kasraei ${ }^{4}$ \\ ${ }^{1}$ Department of Operative Dentistry, School of Dentistry, Tabriz University of Medical Sciences, Tabriz, Iran \\ ${ }^{2}$ Department of Restorative Dentistry, School of Dentistry, Jundishapour University of Medical Sciences, Ahwaz, Iran \\ ${ }^{3}$ School of Dentistry, Tabriz University of Medical Sciences, Tabriz, Iran \\ ${ }^{4}$ Dental Research Center, Department of Restorative Dentistry, School of Dentistry, Hamadan University of Medical \\ Sciences, Hamadan, Iran
}

\author{
*Correspondence to \\ Sarah Gholizadeh, Assistant \\ Professor, Department of Restorative \\ Dentistry, School of Dentistry, \\ Jundishapour University of Medical \\ Sciences, Ahwaz, Iran. \\ Tel: +98 6133205168; \\ Fax: +986133205170 \\ Email: \\ sarah.gholizadeh92@gmail.com
}

Published online 27 September 2017

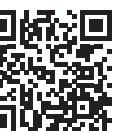

\begin{abstract}
Introduction: Successful repair of composite restorations depends on a strong bond between the old composite and the repair composite. This study sought to assess the repair shear bond strength of aged silorane-based composite following surface treatment with Nd:YAG, Er,Cr:YSGG and $\mathrm{CO} 2$ lasers.

Methods: Seventy-six Filtek silorane composite cylinders were fabricated and aged by 2 months of water storage at $37^{\circ} \mathrm{C}$. The samples were randomly divided into 4 groups $(n=19)$ of no surface treatment (group 1) and surface treatment with Er,Cr:YSGG (group 2), Nd:YAG (group 3) and CO2 (group 4) lasers. The repair composite was applied and the shear bond strength was measured. The data were analyzed using one-way analysis of variance (ANOVA) and Tukey posthoc test. Prior to the application of the repair composite, 2 samples were randomly selected from each group and topographic changes on their surfaces following laser irradiation were studied using a scanning electron microscope (SEM). Seventeen other samples were also fabricated for assessment of cohesive strength of composite.

Results: The highest and the lowest mean bond strength values were $8.99 \mathrm{MPa}$ and $6.69 \mathrm{MPa}$ for Er,Cr:YSGG and control groups, respectively. The difference in the repair bond strength was statistically significant between the Er,Cr:YSGG and other groups. Bond strength of the control, $\mathrm{Nd}$ :YAG and CO2 groups was not significantly different. The SEM micrographs revealed variable degrees of ablation and surface roughness in laser-treated groups.

Conclusion: Surface treatment with Er,Cr:YSGG laser significantly increase the repair bond strength of aged silorane-based composite resin.

Keywords: Silorane-based composite; Surface treatment; Laser; Aging.
\end{abstract}

\section{Introduction}

Despite the improved long-term clinical service of toothcolored restorations, chipping, wear and small fractures still occur and are the main reasons for replacement of these restorations. ${ }^{1,2}$

In most cases, intraoral repair of restorations is preferred to their replacement. ${ }^{3}$ Adhesive dentistry is based on conservative cavity preparation and use of adhesive restorative materials. This approach not only enables conservative caries removal, but also allows for the repair of existing restorations instead of their replacement. ${ }^{4}$ Clinical service of composite restorations depends on the properties of their polymer network and fillers. ${ }^{5-7}$ These properties are different in various types of composites and are important for assessing the efficacy of different surface treatment methods for composite restoration repair. ${ }^{8}$ Uniformity and compatibility of the repair composite with the old composite are achieved via 3 mechanisms namely chemical bond to the organic matrix, chemical bond to the exposed filler particles and micromechanical interlocking. ${ }^{9}$ Previous studies have shown the optimal efficacy of micromechanical retention created by diamond burs, sandblasting and acid etching for increasing the repair bond strength of composite. ${ }^{10,11}$ Laser has been recently used for surface roughening in dental procedures and Er,Cr:YSGG, $\mathrm{CO}_{2}$ and $\mathrm{Nd}$ :YAG lasers have been used for this purpose. ${ }^{12-16}$

On the other hand, silorane-based composites with ring opening polymerization mechanism were introduced to overcome the polymerization shrinkage and the

Please cite this article as follows: Alizadeh Oskoee P, Savadi Oskoee S, Rikhtegaran S, et al. Effect of various laser surface treatments on repair shear bond strength of aged silorane-based composite. J Lasers Med Sci. 2017;8(4):186-190. doi:10.15171/jlms.2017.34. 
subsequently created stresses in dimethacrylate-based composites. ${ }^{17,18}$ Irrespective of the structural differences of composites, repair or replacement of restorations is often required after a period of clinical service due to wear, discoloration or chipping of composites. Thus, age of a restoration plays a fundamental role in repair bond strength of composites. ${ }^{19,20}$ Aging causes hydrolytic degradation of resin matrix and silanizes non-organic fillers in the oral cavity. ${ }^{21} \mathrm{~A}$ previous study on repair of composites showed significant reduction in bond strength at the interface of aged and new composite. ${ }^{22}$ Considering the effect of aging on the success of composite repair and the significance of repair bond strength in low-shrinkage silorane-based composites, this study aimed to assess the effect of surface treatments with Er,Cr:YSGG, Nd:YAG and $\mathrm{CO}_{2}$ lasers on repair shear bond strength of aged Filtek silorane composite.

\section{Methods}

In this in vitro study, 76 cylindrical composite samples measuring $6 \mathrm{~mm}$ in diameter and $4 \mathrm{~mm}$ in height were fabricated of Filtek silorane composite resin (3M ESPE Dental Products, St. Paul, MN, USA). The composite resin was incrementally applied in 2 layers to a plastic mold and each layer was cured for 40 seconds using a light-curing unit (Astralis 7, Ivoclar Vivadent, Schaan, Lichtenstein) with a light intensity of $400 \mathrm{~mW} / \mathrm{cm}^{2}$. The final layer was covered with a Mylar strip and after curing, the samples were polished by Soflex polishing discs up to 1000 grit (3M ESPE, St. Paul, MN, USA) and were then stored in distilled water at $37^{\circ} \mathrm{C}$ for 2 months for the purpose of aging. Table 1 presents the properties of the materials and lasers used in this study. Seventy-six aged samples were divided into 4 groups $(n=19)$ based on the type of surface treatment:

Group 1: No surface treatment.

Group 2: The samples were subjected to Er,Cr:YSGG (Biolase Europe GmbH, 92685 Floß, Germany) laser irradiation with a fiber optic tip diameter of $400 \mu$. It generated photons at a wavelength of $2780 \mathrm{~nm}$ with 20 $\mathrm{Hz}$ frequency, $3 \mathrm{~W}$ output power, $150 \mathrm{~mJ}$ energy per pulse and $200 \mu$ s pulse duration. The laser tip was used perpendicularly at $1 \mathrm{~mm}$ distance from the surface under $50 \%$ water and $60 \%$ air spray with 2 bar pressure. The application tip was swiped across the surface from the center of the composite disc to the peripheries with a circular movement for 5 seconds.

Group 3: The samples were subjected to Nd:YAG dental laser (Lambada Scientifica, Srl, Vicenza, Italy) irradiation with a fiber diameter of $400 \mu$. It generated photons at a wavelength of $1064 \mathrm{~nm}$ with $20 \mathrm{~Hz}$ frequency, $3 \mathrm{~W}$ output power, $150 \mathrm{~mJ}$ energy per pulse and $200 \mu$ s pulse duration. The laser tip was used perpendicularly at $1 \mathrm{~mm}$ distance from the surface under 50\% water and $60 \%$ air spray with 2 bar pressure. The application tip was swiped across the surface from the center of the composite disc to the peripheries with a circular movement for 5 seconds.

Group 4: The samples were subjected to $\mathrm{CO}_{2}$ surgical laser (Lambada Scientifica, Srl, Vicenza, Italy) irradiation. The laser handpiece had a hollow tube with a tip diameter of $400 \mu$. It generated photons at a wavelength of $10.6 \mu \mathrm{m}$ with $20 \mathrm{~Hz}$ frequency, 3W output power, $150 \mathrm{~mJ}$ energy per pulse and $200 \mu$ s pulse duration. The laser tip was used perpendicularly at $1 \mathrm{~mm}$ distance from the surface under $50 \%$ water and $60 \%$ air spray with 2 bar pressure. The application tip was swiped across the surface from the center of the composite disc to the peripheries with a circular movement for 5 seconds.

In all groups, composite surfaces were laser-irradiated at $2 \mathrm{~mm}$ distance for 15 seconds. The treated surfaces were rinsed with distilled water and dried. Silorane bonding agent (3M ESPE, St. Paul, MN, USA) was applied to the surface and light cured for 10 seconds. According to the manufacturer's instructions. A plastic mold measuring 2 $\mathrm{mm}$ in height and $4 \mathrm{~mm}$ in diameter was placed at the center of the surfaces. One layer of composite with 2

Table 1. The Properties of the Materials and Lasers Used in This Study

\begin{tabular}{|c|c|c|}
\hline Material & Description \& Composition & Manufacturer \\
\hline $\begin{array}{l}\text { Filtek }^{\mathrm{TM}} \text { silorane, low } \\
\text { shrinkage posterior } \\
\text { restorative material }\end{array}$ & $\begin{array}{l}\text { A light curing radiopaque silorane-based composite. The monomer matrix is } \\
\text { composed of siloxane and oxirane molecules ( } 23 \% \text { of the composition). The } \\
\text { inorganic filler contains fine quartz particles and radiopaque yttrium fluoride } \\
\text { ( } 76 \%) \text {. } \\
\text { Additional contents: initiator }(0.9 \%) \text {, stabilizer }(0.13 \%) \text { and pigments }(0.005 \%) \text {. }\end{array}$ & $\begin{array}{l}\text { 3M ESPE Dental Products, St. } \\
\text { Paul, MN, USA }\end{array}$ \\
\hline Filtek silorane bond & $\begin{array}{l}\text { A filled, light-cure bonding agent for enamel and dentin bonding. It contains a } \\
3 \mathrm{M} \text { ESPE hydrophobic bifunctional monomer, camphor quinine/silane-treated } \\
\text { silicofillers and stabilizer. }\end{array}$ & $\begin{array}{l}3 \text { M ESPE Dental Product, St. } \\
\text { Paul, MN, USA }\end{array}$ \\
\hline CO2 laser & $\begin{array}{l}\text { Carbon dioxide laser, wavelength }=10600 \text { nanometers, repetition rate }=20 \mathrm{~Hz} \text {, } \\
\text { pulse duration }=140 \text { microseconds. }\end{array}$ & $\begin{array}{l}\text { LAMBDA ScientificaSrl, } \\
\text { Vicenza, Italy }\end{array}$ \\
\hline Er,Cr:YSGG laser & $\begin{array}{l}\text { Erbium, chromium: } y \text { ttrium-scandium -gallium-garnet wavelength }=2780 \\
\text { nanometers, repetition rate }=20 \mathrm{~Hz} \text {, pulse duration }=140 \text { microseconds. }\end{array}$ & $\begin{array}{l}\text { Biolase Europe } \mathrm{GmbH} \text {, Floss, } \\
\text { Germany }\end{array}$ \\
\hline Nd:YAG laser & $\begin{array}{l}\text { Neodymium:Yttrium-aluminum-garnet wavelength }=1064 \text { nanometers, } \\
\text { repetition rate }=20 \mathrm{~Hz} \text {, pulse duration }=140 \text { microseconds. }\end{array}$ & $\begin{array}{l}\text { Nd:YAG Dental Laser, } \\
\text { LAMBADA Scientifica, Srl, } \\
\text { Vicenza, Italy }\end{array}$ \\
\hline
\end{tabular}


mm thickness was applied and cured for 40 seconds. The mold was then removed and the samples were light cured repeatedly from different directions for 20 seconds.

A universal testing machine was used for measurement of shear bond strength. The upper fixture was attached to the superior jaw of the machine and the lower fixture with the sample was mounted on the inferior jaw of the machine. The crosshead blade was adjusted at the newold composite interface and the load at fracture of the samples displayed on the monitor was recorded. The load was applied by the chisel-shaped blade of the machine at a crosshead speed of $1 \mathrm{~mm} /$ minute vertical to the oldnew composite interface. The values were recorded in newton $(\mathrm{N})$ and converted to megapascal ( $\mathrm{MPa})$ using the formula below:

$$
\text { Repair bond strength }(M P a)=\frac{\operatorname{Force}(N)}{\text { Sample surface area }(\mathrm{mm} 2)}
$$

In groups 1 to 4 , prior to applying the repair composite, 2 samples were randomly chosen and gold sputter-coated with $150 \mathrm{~A}^{\circ}$ thickness in vacuum conditions $\left(10^{3} \mathrm{mbr}\right)$. The surface topography of these samples was studied under a scanning electron microscope (SEM) (Tescan Vega-II, Tescan S.RO, Libusinia Trida, Czech Republic). The repair shear bond strength data were analyzed using one-way analysis of variance (ANOVA) and post hoc Tukey test at $P=0.05$ level of significance.

\section{Results}

Table 2 shows the shear bond strength values of the 4 groups. As seen in Table 2, the highest and the lowest shear bond strength values were seen in the Er,Cr:YSGG $(8.99 \pm 1.16 \mathrm{MPa})$ and the control $(6.69 \pm 1.68 \mathrm{MPa})$ groups, respectively. One-way ANOVA revealed a significant difference in the repair bond strength of the 4 groups $(P<0.0001)$. Pairwise comparison of the groups with the Tukey post-hoc test revealed that the mean bond strength of Er,Cr:YSGG group was significantly different from that of the other groups $(P<0.05$, Table 3$)$. However, no significant differences were noted between shear bond strength values of the $\mathrm{CO}_{2}$, control and $\mathrm{Nd}$ :YAG laser groups $(P>0.05$, Table 2$)$.

The SEM micrographs revealed micro-porous and irregular patterns in the Er,Cr:YSGG laser treated surfaces. In the groups treated with $\mathrm{CO}_{2}$ and $\mathrm{Nd}$ :YAG lasers, ablated areas and increased surface roughness (but with a different pattern from that of erbium laser group)
Table 2. Comparison of the Mean Shear Bond Strength (MPa) Values in the Study Groups

\begin{tabular}{lccc}
\hline \multirow{2}{*}{ Groups } & Mean \pm SD & \multicolumn{2}{c}{$\mathbf{9 5 \%} \mathbf{C l}$ of the Mean } \\
\cline { 3 - 4 } & & Lower Bound & Upper Bound \\
\hline Control & $6.69 \pm 1.68$ & 5.8286 & 7.5644 \\
Er,Cr:YSGG & $8.99 \pm 1.16$ & 8.3897 & 9.5903 \\
CO2 & $7.20 \pm 1.27$ & 6.5440 & 7.8583 \\
Nd:YAG & $7.33 \pm 1.16$ & 6.7401 & 7.9352 \\
\hline
\end{tabular}

ane-way ANOVA, $P=0001$.

were seen (Figure 1A-D).

\section{Discussion}

Repair of aged composites is a minimally invasive and costeffective procedure. Several surface treatment methods have been introduced to enhance micromechanical retention and increase the wettability of old composites such as acid etching, diamond bur preparation, sandblasting and laser irradiation. ${ }^{21}$ The immediate repair bond strength of composite is similar to its cohesive strength due to the presence of oxygen inhibited layer. However, after aging, factors such as decreased amount
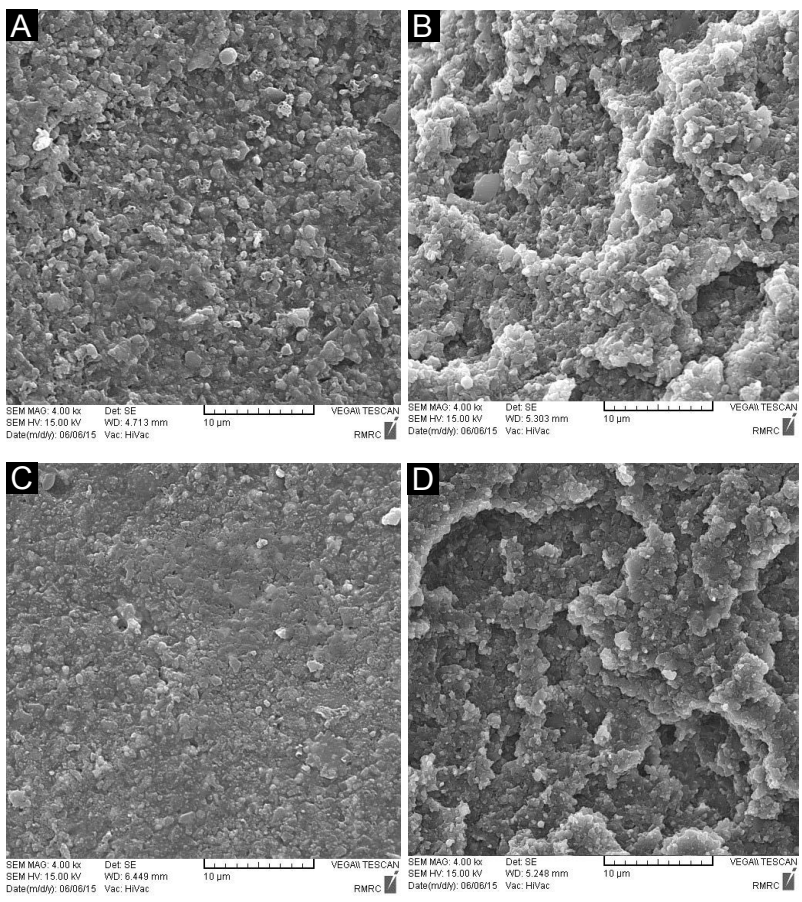

Figure 1. (A) Er,Cr:YSGG Laser Treated Surface. (B) Nd:YAG Laser Treated Surface. (C) CO2 Laser Treated Surface. (D) Surface Topography of the Control Group.

Table 3. Pairwise Comparisons of the Groups Using the Tukey Test

\begin{tabular}{|c|c|c|c|c|c|c|c|}
\hline Group & Group & Mean Differences & $P$ Value $^{\mathrm{a}}$ & Group & Group & Mean Differences & $P$ Value $^{\mathrm{a}}$ \\
\hline Er,Cr:YSGG & Control & 2.29 & 0.000 & Er,Cr:YSGG & $\mathrm{Co}_{2}$ & 1.78 & 0.001 \\
\hline $\mathrm{CO}_{2}$ & Control & 0.50 & 0.693 & Er,Cr:YSGG & $\mathrm{Nd}: Y A G$ & 1.66 & 0.003 \\
\hline $\mathrm{Nd}: Y A G$ & Control & 0.64 & 0.508 & $\mathrm{Nd}: Y A G$ & $\mathrm{Co}_{2}$ & 0.46 & 0.991 \\
\hline
\end{tabular}

a Tukey HSD test. 
of active monomers, polishing and structural changes affect the repair bond strength of composite. ${ }^{21,23}$ On the other hand, differences in the structure of polymer matrix and fillers can yield variable bond strength values. ${ }^{24,25}$ This study aimed to assess the effect of surface treatments with different types of lasers on repair bond strength of aged silorane-based composite. Based on the results, the minimum and maximum bond strength values were noted in the control and Er,Cr:YSGG laser groups, respectively with significant differences with the other groups $(P=0001)$. The results of our study were in line with those of Alizadeh Oskoee et al. ${ }^{26}$

Erbium lasers enable selective ablation and are used for surface treatment of composite restorations. ${ }^{27,28}$ Composite resin ablation by erbium laser is done through explosive vaporization followed by hydrodynamic ejection. ${ }^{27}$ During this process, quick melting and consequently changed volume of the melted material generate strong expansion forces. The generated forces within the composite structure form, prominences on the composite surface and melted material leaks out of the composite surface in the form of drops. ${ }^{29}$ This type of ablation has also been reported to occur following the application of Er,Cr:YSGG laser. ${ }^{27-30}$ The SEM micrographs showed round porosities without smear layer on the Er,Cr:YSGG laser treated surfaces (Figure 1A).The micro-retentive pattern of the surface of samples can increase the repair bond strength via increasing the surface area and balancing stress distribution, ${ }^{31}$ which explains the obtained results in the Er,Cr:YSGG laser group in our study. On the other hand, low repair bond strength in the control group with no surface treatment highlights the important role of surface roughness in achieving optimal repair bond strength. ${ }^{11,32}$ A noteworthy finding of the current study was that, although the repair bond strength of $\mathrm{Nd}$ :YAG and $\mathrm{CO}_{2}$ laser groups was higher than that of the control group, the difference in values among the 3 groups did not reach statistical significance $(P>0.05)$; this finding was in contrast to the results of Alizadeh Oskoee et $\mathrm{al}^{26}$

Evaluation of the SEM micrographs of the surfaces treated with $\mathrm{Nd}$ :YAG and $\mathrm{CO}_{2}$ lasers showed degradation of resin matrix, ablation and increased surface roughness with a different pattern from that in the Er,Cr:YSGG laser group (Figure $1 \mathrm{~B}$ and $1 \mathrm{C}$ ).

In the clinical process, aging occurs due to the exposure of composite material to the oral environment, foods and drinks as well as cyclic loading over long periods of time, which change the structure of the material. ${ }^{21,23}$ Water storage is the most efficient aging protocol due to its hydrolytic effect on the matrix and filler interface. ${ }^{21}$ During water storage, water is absorbed by the resin matrix via the diffusion mechanism and weakens the matrix and causes the leakage of unreacted monomers into the environment leading to eventual failure of resinfiller bond. ${ }^{23}$
It seems that water storage causes structural changes in the samples and consequently yields repair bond strength values different from those in immediate repair conditions. ${ }^{26}$ According to Beyer et $a{ }^{33}$ the optimal clinical repair bond strength is $60 \%-70 \%$ of the cohesive strength of composite. Thus, it seems that laser irradiation is not suitable for surface treatment of aged silorane-based composites; however, generalization of the results to the clinical setting requires further studies with different methods and durations of aging.

\section{Conclusion}

Surface treatment with Er,Cr:YSGG laser significantly increases the repair bond strength of aged silorane-based composite resin.

\section{Ethical Considerations}

This study was approved by the ethical committee of the Vice Chancellor of Research, Tabriz University of Medical Sciences.

\section{Conflict of Interests}

The authors declare that they have no conflict of interest.

\section{Acknowledgments}

The authors would like to thank the Dental Research Center and the Vice Chancellor of Research of Tabriz University of Medical Sciences for supporting this study.

\section{References}

1. Gregory WA, Berry S, Duke E, Dennison JB. Physical properties and repair bond strength of direct and indirect composite resins. J Prosthet Dent. 1992;68(3):406-411.

2. Lucena-Martin C, Gonzalez-Lopez S, Navajas-Rodriguez de Mondelo JM. The effect of various surface treatments and bonding agents on the repaired strength of heat-treated composites. J Prosthet Dent. 2001;86(5):481-488.

3. Oztas N, Alacam A, Bardakcy Y. The effect of air abrasion with two new bonding agents on composite repair. Oper Dent. 2003;28(2):149-54.

4. Rodrigues SA Jr, Ferracane JL, Della Bona A. Influence of surface treatments on the bond strength of repaired resin composite restorative materials. Dent Mater. 2009;25(4):442-451. doi: 10.1016/j.dental.2008.09.009.

5. Ferracane JL. Hygroscopic and hydrolytic effects in dental polymer networks. Dent Mater. 2006;22(3):211-222. doi: 10.1016/j.dental.2005.05.005.

6. Sideridou I, Tserki V, Papanastasiou G. Study of water sorption, solubility and modulus of elasticity of lightcured dimethacrylate-based dental resins. Biomaterials. 2003;24(4):655-665.

7. Kalachandra S. Influence of fillers on the water sorption of composites. Dent Mater. 1989;5(4):283-288.

8. Gordan VV, Mjor IA, Blum IR, Wilson N. Teaching students the repair of resin-based composite restorations: a survey of North American dental schools. J Am Dent Assoc. 2003;134(3):317-323.

9. Brosh T, Pilo R, Bichacho N, Blutstein R. Effect of 
combinations of surface treatments and bonding agents on the bond strength of repaired composites. J Prosthet Dent. 1997;77(2):122-126.

10. Bouschlicher MR, Reinhardt JW, Vargas MA. Surface treatment techniques for resin composite repair. Am J Dent. 1997;10(6):279-283.

11. Bonstein T, Garlapo D, Donarummo J Jr, Bush PJ. Evaluation of varied repair protocols applied to aged composite resin. J Adhes Dent. 2005;7(1):41-49.

12. Hossain M, Nakamura Y, Yamada Y, Suzuki N, Murakami Y, Matsumoto K. Analysis of surface roughness of enamel and dentin after Er,Cr:YSGG laser irradiation. $J$ Clin Laser Med Surg. 2001;19(6):297-303. doi: $10.1089 / 104454701753342749$.

13. Usumez A, Aykent F. Bond strengths of porcelain laminate veneers to tooth surfaces prepared with acid and Er,Cr:YSGG laser etching. J Prosthet Dent. 2003;90(1):2430. doi: 10.1016/s002239130300235x.

14. Dumore T, Fried D. Selective ablation of orthodontic composite by using sub-microsecond IR laser pulses with optical feedback. Lasers Surg Med. 2000;27(2):103-10.

15. Chan KH, Hirasuna K, Fried D. Rapid and selective removal of composite from tooth surfaces with a 9.3 microm CO2 laser using spectral feedback. Lasers Surg Med. 2011;43(8):824-832. doi: 10.1002/lsm.21111.

16. Alexander R, Xie J, Fried D. Selective removal of residual composite from dental enamel surfaces using the third harmonic of a Q-switched Nd:YAG laser. Lasers Surg Med. 2002;30(3):240-245.

17. Weinmann W, Thalacker C, Guggenberger R. Siloranes in dental composites. Dent Mater. 2005;21(1):68-74. doi: 10.1016/j.dental.2004.10.007.

18. Guggenberger R, Weinmann W. Exploring beyond methacrylates. Am J Dent. 2000;13(Spec No):82D-84D.

19. Soderholm KJ, Roberts MJ. Variables influencing the repair strength of dental composites. Scand J Dent Res. 1991;99(2):173-180

20. Yap AU, Sau CW, Lye KW. Effects of aging on repair bond strengths of a polyacid-modified composite resin. Oper Dent. 1999;24(6):371-376.

21. Ozcan M, Barbosa SH, Melo RM, Galhano GA, Bottino MA. Effect of surface conditioning methods on the microtensile bond strength of resin composite to composite after aging conditions. Dent Mater. 2007;23(10):1276-1282. doi: 10.1016/j.dental.2006.11.007.
22. Shiau JY, Rasmussen ST, Phelps AE, Enlow DH, Wolf GR. Analysis of the "shear" bond strength of pretreated aged composites used in some indirect bonding techniques. J Dent Res. 1993;72(9):1291-1297. doi: 10.1177/00220345930720090601.

23. Brendeke J, Ozcan M. Effect of physicochemical aging conditions on the composite-composite repair bond strength. J Adhes Dent. 2007;9(4):399-406.

24. Denehy G, Bouschlicher M, Vargas M. Intraoral repair of cosmetic restorations. Dent Clin North Am. 1998;42(4):71937.

25. Ramoglu SI, Usumez S, Buyukyilmaz T. Accelerated aging effects on surface hardness and roughness of lingual retainer adhesives. Angle Orthod. 2008;78(1):140-144. doi: 10.2319/112106-473.1.

26. Alizadeh Oskoee P, Mohammadi N, Ebrahimi Chaharom ME, et al. Effect of surface treatment with Er;Cr:YSSG, Nd:YAG, and CO2 lasers on repair shear bond strength of a silorane-based composite resin. J Dent Res Dent Clin Dent Prospects. 2013;7(2):61-66. doi: 10.5681/joddd.2013.011.

27. Correa-Afonso AM, Palma-Dibb RG, Pecora JD. Composite filling removal with erbium:yttrium-aluminum-garnet laser: morphological analyses. Lasers Med Sci. 2010;25(1):17. doi: 10.1007/s10103-008-0581-z.

28. Lizarelli Rde F, Moriyama LT, Bagnato VS. Ablation of composite resins using Er:YAG laser--comparison with enamel and dentin. Lasers Surg Med. 2003;33(2):132-139. doi: $10.1002 / \mathrm{lsm} .10196$.

29. Lizarelli RFZ, Moriyama LT, Pelino JEP, Bagnato VS. Ablation rate of morphological aspects of composite resin exposed to Er:YAG laser. Journal of Oral Laser Applications. 2005;5(3):151-160.

30. Lizarelli RFZ, Moriyama LT, Bagnato VS. Ultraconservative ablation in operative and esthetic dentistry. Journal of Oral Laser Applications. 2003;3(2):73-78.

31. Fawzy AS, El-Askary FS, Amer MA. Effect of surface treatments on the tensile bond strength of repaired water-aged anterior restorative micro-fine hybrid resin composite. J Dent. 2008;36(12):969-976. doi: 10.1016/j. jdent.2008.07.014.

32. Hannig C, Laubach S, Hahn P, Attin T. Shear bond strength of repaired adhesive filling materials using different repair procedures. J Adhes Dent. 2006;8(1):35-40.

33. Beyer E, Behter K, Petschke Schweissenmit U. Lasers in Dentistry. 1st ed. Chicago: Quintessence; 1989:231-45. 